\title{
Mulemba
}

Revista Angolana de Ciências Sociais

\section{A educação escolar e a justiça social num mundo global. Reflexões acerca da obra Educação e justiça social de Martha C. Nussbaum}

\section{Maria Isabel Henriques}

\section{Q OpenEdition}

\section{Journals}

Edição electrónica

URL: http://journals.openedition.org/mulemba/310

DOI: $10.4000 /$ mulemba.310

ISSN: 2520-0305

\section{Editora}

Edições Pedago

Edição impressa

Data de publição: 1 novembro 2014

Paginação: 611-618

ISSN: 2182-6471

Refêrencia eletrónica

Maria Isabel Henriques, «A educação escolar e a justiça social num mundo global. Reflexões acerca da obra Educação e justiça social de Martha C. Nussbaum», Mulemba [Online], 4 (8) | 2014, posto online no dia 20 novembro 2016, consultado o 26 janeiro 2021. URL: http://journals.openedition.org/ mulemba/310 ; DOI: https://doi.org/ERREUR PDO dans /localdata/www-bin/Core/Core/Db/ Db.class.php L.34 : SQLSTATE[HY000] [2006] MySQL server has gone away

Este documento foi criado de forma automática no dia 26 janeiro 2021.

Tous droits réservés 


\title{
A educação escolar e a justiça social num mundo global. Reflexões acerca da obra Educação e justiça social de Martha C. Nussbaum
}

\author{
Maria Isabel Henriques
}

\section{NOTA DO AUTOR}

Texto da apresentação pública da obra de Martha C. NUSSBAUM, Educação e justiça social (Tradução de Graça Lami, revisão do texto de Luísa Matos. Mangualde, Edições Pedago, 2014, 124p. [«Contrapontos», colecção coordenada por João M. Paraskeva]), lido por ocasião das «Actividades alusivas a abertura do II semestre do ano lectivo de 2014», no anfiteatro da Faculdade de Ciências Sociais (FCS) da Universidade Agostinho Neto (UAN), em Luanda, no dia 21 de Agosto de 2014.

1 A convite do Senhor Decano da Faculdade de Ciências Sociais, Professor Doutor Víctor Kajibanga, é com grande prazer e honra que tomo a palavra neste "Ciclo de Actividades» em que se inclui a apresentação da obra de Martha C. Nussbaum, Educação e justiça social.

2 Martha Craven Nussbaum é uma filósofa americana, professora na Universidade de Chicago, particularmente interessada em filosofia grega, romana, política e ética. Durante a década de 1980 colaborou intensamente com Amartya Sen, em projectos de investigação sobre a temática do desenvolvimento. A sua relação com Sen manteve-se, e, na sequência desse trabalho, Nussbaum foi dando uma crescente atenção à análise das políticas públicas para a educação escolar e à relação destas com a justiça social. Este livro resulta de uma selecção de textos da autora que se encontravam dispersos e que aqui foram reunidos em língua portuguesa. Os argumentos apresentados 
encontram-se expandidos nas obras da autora publicadas em língua inglesa, algumas delas traduzidas no Brasil.

3 Para Nussbaum, uma teoria de Justiça Social deve levar em conta noções morais como o valor da dignidade humana. Na sua perspectiva, justiça e direitos humanos devem caminhar juntos. No entanto, prefere substituir a expressão direitos humanos pelo termo capacidades, termo este proposto por Amartya Sen, que, juntamente com Martha Nussbaum, viria a apresentar uma abordagem inovadora à temática do desenvolvimento baseada na expansão das capacidades humanas como condição básica de liberdade e de justiça. Para Nussbaum, seguindo de perto o pensamento de Amartya Sen (2012), existe um conjunto central de capacidades inerentes ao desenvolvimento harmonioso da pessoa humana. Considerando que o preenchimento destas capacidades permite que os indivíduos tenham uma vida plena, a autora considera que as mesmas devem ser objecto de políticas públicas.

4 Conforme defende a autora, o direito à educação constitui um pressuposto essencial para o desenvolvimento humano, já que é condição para a aquisição de hábitos de leitura, sendo, por sua vez, os hábitos de leitura uma condição para o uso do raciocínio moral. Porém, segundo Nussbaum, a igualdade de acesso a esse direito não pode ser pensada como uma igualdade entre iguais, já que aflui às escolas uma ampla diversidade de pessoas, com capacidades e interesses distintos, mas igualmente dignas de uma vida plena e justa. Desta forma, ao longo das suas reflexões, a autora pretende encontrar respostas para uma das suas grandes preocupações: Uma sociedade e uma educação mais justas são possíveis?

o livro, de 124 páginas, é composto por quatro capítulos atravessados pela ideia central de que nada é mais determinante para um Estado democrático do que a educação dos seus cidadãos. Como fica escrito no próprio resumo da obra, «é durante os anos decisivos ao longo dos quais as crianças e os jovens estudantes frequentam o ensino [Primário e] Secundário que lhes vão sendo incutidos os hábitos de pensamento que os acompanharão até ao fim da sua vida. Poderão aprender a fazer perguntas ou não; a não questionar tudo aquilo que thes é dito ou a levar a cabo uma investigação pessoal mais aprofundada; a imaginar a situação em que se encontram as pessoas que não são iguais a eles ou a considerar que tais pessoas representam uma ameaça para o sucesso dos seus projectos pessoais; a encararem-se a si próprios como fazendo parte de um grupo homogéneo ou a imaginar que o mundo pertence a muitas pessoas e grupos e que, nesse mundo, todos eles merecem respeito e compreensão.»

6 Ao longo do primeiro capítulo, Nussbaum discute a necessidade de estabelecer um equilíbrio entre aquelas que identifica como duas perspectivas da educação escolar no seio dos Estados-nação: a educação patriótica e a educação cosmopolita. Defende a autora que não obstante seja necessário e importante prestar atenção aos valores e tradições de cada comunidade nacional «o sistema educativo deve [conceder]... importância, isto é, [deve] incluir todos os seres humanos na [sua] comunidade de diálogo e de interesse e basear as... decisões políticas neste princípio de inclusão, respeitando o círculo que define a... humanidade e dando-lhe uma particular atenção» (p. 14). O que se pretende afirmar, em termos educativos, é que os estudantes, desde tenra idade, deverão aprender sobre a diferença, interior e exterior às suas nações, para poderem reconhecer ideais e valores comuns e ainda conhecer o suficiente para ter a capacidade de perceber as diferentes culturas e histórias que lhes permitem uma leitura cosmopolita do mundo. 
7 Deste ponto de vista, para Martha Nussbaum, a educação cosmopolita «permite adquirir um maior auto-conhecimento» (p. 16). A autora apoia este argumento em quatro pontos essenciais para reivindicar a ideia de que uma Cidadania Mundial se possa constituir como tema central da educação escolar. Acredita que as crianças deverão ser alertadas para o facto de que se existe um planeamento global, um conhecimento de certa forma global e o reconhecimento de que o futuro é comum, não faz sentido que a educação não seja pensada da mesma forma, ou seja, de forma relacional. Muito embora a educação deva dedicar-se ao estudo da história e da política nacionais, é importante tomar conhecimento da cultura e das tradições dos povos para que este tipo de «diálogo global» (p. 18), seja posto em prática e se consiga estar à altura de respeitar a diferença. Na perspectiva da autora, aquilo que apresenta como uma educação cosmopolita pode ajudar a tomar este tipo de orientação. Insiste a autora que quando limitamos o nosso pensamento «às fronteiras de uma nação» (p. 21), recusando adoptar uma perspectiva mais vasta e global das problemáticas contemporâneas, estamos a «minar o conceito de respeito multicultural» (p. 21) que é, no seu entender, uma perspectiva educativa fundamental.

8 No segundo capítulo a autora salienta a forma como «ao longo da sua carreira, Amartya Sen tem dedicado uma especial atenção à temática da justiça social» (p. 25). Apresenta de uma forma sucinta algumas ideias de Sen sobre esta matéria, em especial as suas preocupações com a desigualdade de género, que tem sido particularmente importante no seu pensamento. Contrariando a ideologia dominante que se centra no crescimento económico como indicador de qualidade de vida de um país, Amartya Sen «tem chamado a atenção para a importância das capacidades» (p. 25) afirmando que essas são os verdadeiros indicadores daquilo que as pessoas são capazes de fazer e de ser. Um dos interesses de Sen são as diferenças sociais, em particular aquelas que estão directamente relacionadas com os vários tipos de desigualdade ${ }^{1}$ que se encontram bem enraizados... «num mundo social [que] é destinado às pessoas que possuem um conjunto típico de capacidades e incapacidades e não àqueles cuja condição é atípica» (p. 30).

9 Pensar a educação escolar nesta linha implica necessariamente considerar o quão ela poder ser indutora e reprodutora de desigualdades sociais (PARASKEVA 2008; BOURDIEU e PASSERON 2009). Uma abordagem da justiça social centrada nas capacidades é de facto «uma forma valiosa» (p. 30) de incorporar na educação escolar os direitos fundamentais, que só poderão ser defendidos com uma maior eficácia se as capacidades para serem cumpridos existirem. Desta forma, caberá aos sistemas educativos estruturarem-se e funcionarem de forma que promovam esses direitos constantemente, em todos os espaços e actividades escolares, tanto curriculares como extra-curriculares. Pensar a educação desta maneira, intensamente democrática, será entender a justiça social como uma espécie de cavalo de Tróia da cultura escolar dominante (SANTOMÉ 2011).

10 Nussbaum explicita o seu apoio à criação de uma lista específica de «Capacidades Humanas Centrais» (p. 41) que seja útil, simultaneamente como instrumento de comparação da qualidade de vida e de formulação dos princípios políticos subjacentes ao desenvolvimento de políticas públicas. A ideia que a autora quer transmitir quanto à abordagem das capacidades assenta na dignidade do ser humano e naquilo que possa ser considerado como "funcionamento verdadeiramente humano» (p. 41), seguindo a formulação de Marx nos seus Manuscritos económico-filosóficos de 1844. Tomando esta ideia como ponto de partida, a autora procura firmar uma lista da qual fazem parte dez 
capacidades que considera como qualidades fundamentais para uma vida com dignidade. Essas dez capacidades são entendidas com objectivos gerais que poderão ser especificados pela sociedade e pelas organizações sociais como sejam as instituições educativas. Toda a sociedade que não garanta o desenvolvimento desses objectivos pelos seus cidadãos correrá o risco de não poder ser considerada uma sociedade justa, uma vez que todas as capacidades apresentadas pela autora devem à partida ser consideradas fundamentais para o desenvolvimento integral de toda e qualquer pessoa.

11 No terceiro capítulo, Martha Nussbaum socorre-se de vários exemplos da Índia, cujo sistema educativo conheceu e estudou. Descreve, por exemplo, entre outros aspectos, a existência daquilo que designa por uma educação rural tipicamente pobre, onde as aulas decorrem no chão, ao ar livre. Uma educação desprovida de recursos, onde apenas existem algumas ardósias e onde quase não há papel. Mas apesar de tudo isso, o que Nussbaum destaca é que esta é também frequentemente uma educação criativa e apaixonante. Segundo a autora, essa criatividade baseia-se nalguns pontos essenciais, designadamente: i) o facto de existir uma forte ligação entre a educação e o pensamento crítico relativamente ao próprio ambiente social; ii) a importância das artes como aspecto fundamental da experiência educativa das crianças e dos jovens; iii) a imensa paixão e capacidade dos professores para fazerem mais e melhor sempre que sentirem progressos em cada um dos seus alunos.

12 A preocupação da autora em destacar exemplos desta natureza prende-se com a ideia de que uma educação de qualidade será aquela que privilegie e desenvolva o pensamento crítico e criativo dos estudantes, promovendo aprendizagens significativas de acordo com as suas vivências sociais. Na opinião de Nussbaum, a mais importante tarefa educativa consiste em saber como desenvolver o pensamento crítico e criativo das crianças que mais tarde serão os futuros cidadãos democratas de um país, o que exige preocupações acrescidas quanto à importância que habitualmente é dada à obrigatoriedade dos manuais escolares, às questões da tecnologia educativa, à adopção de determinadas metodologias de trabalho, entre outros aspectos.

13 Nussbaum defende que se considere e se dê elevada importância ao que até agora se tem vindo a ignorar, ou seja, a relação entre as «capacidades», as «humanidades» e as «artes» para a formação plena de uma cidadania democrática. Lembra-nos que estas ideais não são novas e que vêm sendo defendidas há muitas de décadas por diversos pensadores, como por exemplo John Dewey, nos Estados Unidos da América, e Tagore, na Índia. Na sequência destas ideias, Nussbaum defende a existência de três capacidades fundamentais ao aperfeiçoamento da cidadania democrática, sendo elas: i) a capacidade de auto-crítica sobre si mesmo e a suas suas tradições; ii) a capacidade de raciocínio-lógico, no sentido de que os cidadãos estejam aptos e atentos, desenvolvendo o pensamento crítico tão decisivo para uma cidadania activa e responsável numa sociedade democrática pluralista (esta capacidade é relevante para os estudantes desenvolverem uma nova atitude positiva e tolerante perante as opiniões diferentes); iii) a imaginação narrativa, isto é, ser capaz de se colocar no lugar do outro e de avaliar conscientemente a sua história, sendo capaz de compreender os «desejos», os «sentimentos» e «esperanças» (p. 81) de alguém que não de si próprio.

Martha Nussbaum coloca especial enfâse nesta última capacidade que, segundo a autora, desenvolve-se sobretudo pela «literacia» e através das «artes» (p. 81). As artes são uma fonte decisiva para a liberdade e para o espírito comunitário. São «excelentes fontes de alegria e essa alegria far-se-á sentir ao longo de todo o processo educativo das 
crianças» (p. 82) e dos jovens. Inspirando-se em Tagore, a autora defende que a educação deverá ocupar-se «em primeiro lugar da mente da criança e deve ter como principal objectivo o desenvolvimento da liberdade dessa mente no âmbito do seu próprio contexto social» (p. 85). Ilustra essa ideia com um conto de Tagore intitulado «O treino do papagaio» (p. 84). Uma história triste que nos ajuda a refletir no tipo de ensino e de aprendizagem rotineira, tecnicista e alienante que ali está descrito. Para Nussbaum não poderá existir pior forma de educar uma criança do que sujeitá-la a esse tipo de aprendizagem «tecnicista e rotineira» (p. 84).

No quarto e último capítulo deste pequeno livro, Nussbaum centra-se sobretudo nas desigualdades entre os países mais ricos e os países mais pobres. Refere ainda sobre a existência de desigualdades que considera moralmente alarmantes, já que «a qualidade de vida de cada criança é determinada à nascença pela sorte de ter nascido num país e não noutro» (p. 90). Aborda agora a teoria da justiça social no âmbito da teoria do contrato social, que tem tido algum impacto no pensamento global sobre a justiça social, principalmente devido à influência do trabalho de Rawls. Neste capítulo, a autora procura fazer uma análise à teoria do contrato social, centrando-se no pensamento de Rawls e perspectivando as suas ideias à escala global. Identifica nessa teoria o que considera serem algumas fragilidades de ordem estrutural, que, por sua vez, implicam resultados evidentemente imperfeitos. Sustenta ainda que as suas propostas de «abordagem das capacidades» (p. 91) em conjunto com as de Sen proporcionam resultados mais promissores na medida em que, e passo a citar, «promovem um conjunto de direitos... análogos aos direitos humanos» (p. 91).

Dito tudo isto, não duvidemos que a Educação é a chave mestra que permite o desenvolvimento de muitas das capacidades humanas indispensáveis ao desenvolvimento de uma nação. Contudo, a educação escolar é ainda em inúmeros aspectos injusta. Cabe aos governos nacionais o forte investimento na educação, mas também às organizações não-governamentais e toda a sociedade civil, de forma que todos juntos possam percorrer um caminho que se distinga por seguir na direcção da justiça social.

\section{BIBLIOGRAFIA}

ABREU Cesaltina, 2012, «Amartya Sen. Reexaminando a desigualdade», Revista Angolana de Sociologia (Luanda), n. 10, pp. 205-208.

BOURDIEU Pierre e PASSERON Jean-Claude, 2009, A reprodução. Elementos para uma teoria do sistema de ensino. Petrópolis, Vozes.

PARASKEVA João M., 2008, Educação e poder. Abordagens críticas e pós-estruturais. Mangualde, Edições Pedago.

SANTOMÉ J. T., 2011, La justicia curricular. El caballo de Troya de la cultura escolar. Madrid, Ediciones Morata.

SEN Amartya, 2012, A ideia de justiça. Coimbra, Almedina. 


\section{NOTAS}

1. A este respeito, ver a recensão de Cesaltina Abreu ao livro de Amartya Sen, Inequality reexamined (1992, New York, Russel Sage), publicada na Revista Angolana de Sociologia (Luanda), n.ำ 10, pp. 205-208.

\section{AUTOR}

\section{MARIA ISABEL HENRIQUES}

misahenriques@gmail.com

Professora Titular, Ministério da Educação, Portugal.

É professora titular no Agrupamento de Escolas Professor Noronha Feio, em Portugal. É licenciada em Ensino pelo Instituto Superior de Ciências Educativas (ISCE) e pós-graduada em Didáctica da Matemática pelo Instituto de Educação da Universidade de Lisboa. Ao longo da sua carreira de mais de 15 anos na escola pública tem desenvolvido diversos projectos com as crianças, as famílias e as comunidades locais, em que tem trabalhado segundo uma orientação democrática assente em estratégias participativas e deliberativas, com vista ao desenvolvimento de uma pedagogia norteada pelos valores da inclusão e da justiça curricular. 